\title{
Theoretical Assessment of Sustainability Principles for Renewable Smart Air-Conditioning
}

\author{
Tosin T. Oye \\ School of Engineering and the Built Environment, Edinburgh Napier University, UK \\ E-mail: t.oye2@napier.ac.uk
}

Naren Gupta

School of Engineering and the Built Environment, Edinburgh Napier University, UK

E-mail:n.gupta@napier.ac.uk

Keng Goh

School of Engineering and the Built Environment, Edinburgh Napier University, UK

E-mail: k.goh@napier.ac.uk

Toyosi K. Oye

School of Engineering and the Built Environment, Edinburgh Napier University, UK

E-mail: t.oye@napier.ac.uk

Received: May 5, 2020 Accepted: May 30, 2020 Published: June 2, 2020

doi:10.5296/emsd.v9i3.16953 URL: https://doi.org/10.5296/emsd.v9i3.16953

\begin{abstract}
Upon an improvement in the quality of life, air-conditioning has generally been applied. Nevertheless, environmental and health issues related with the use of air-conditioning occurs more often. Therefore, this paper aims to theoretically assess the principles of sustainability to achieve sustainability for renewable smart air-conditioning. Not only with consideration to the geometry (i.e. system mechanisms and components), fuzzy logic control and proportional-integral-derivative that such studies drawn particular attention to, but with concerns to a matter which has been previously ignored. That is with consideration to the
\end{abstract}


potential which the renewable-based options, advanced smart control technique and profitability measures of air-conditioning reinforces the three pillars of sustainability, and their sustainable indicators as context-specific transformations have, to not only eradicate indoor health effects, lower the levels of energy consumption and rate of carbon emissions, but to uncover the significance of and particular contribution renewables and smart control opportunities makes to the sustainability of the system. In meeting this aim and demonstrating the sustainability of the theoretical framework, this paper reveals renewable and smart control system as the fundamental key components of the air-conditioning as it promotes to reduce levels of energy consumption and lower carbon emissions, vis-à-vis establish a comfortable and healthy indoor environment as an exercise in the sustainable theoretical framework whose status as renewable smart air-conditioning not only tackle poor indoor air quality but also combat global warming and climate change.

Keywords: Sustainability, Air-conditioning, Renewable energy, Smart control, Environment, Economic, Social, Energy consumption, Carbon emission, Profitability, Health effect, Climate change

\section{Introduction}

Sustainability has been primarily characterized more than thirty years ago and is broadly acknowledged as a significant conceptual framework inside which to situate municipal development and policy. The basic influence between the related parts of sustainability; economic, social and environment is subsequently varied amid the understanding of idea which has prompted an assortment of municipal structures being depicted as sustainable (Dempsey et al., 2011). As material utilization and energy nodes, urban areas are causally connected to quickening worldwide natural deterioration and are not sustainable through themselves. Concurrently, urban areas and their occupants can undertake a significant work in accomplishing worldwide sustainability (Wilhite, 2009). The scholarly investigation of sustainable development currently holds an assortment of points of view and methodologies. Moreover, it incorporates various practices and policies based on common agrarian utopianism in the direction of capital-intensive large-scale client market growth. The well-being of human remains at the focal point of investigation when considering sustainability and utilization of renewable air-conditionings. The most blazing season in parts of the world as of now brings daily levels of encompassing warmth past the human species physiological limits, especially for individuals undertaking physical labor (Kjellström et al., 2009). Climate change will generate excessive levels of exposure of heat and air-conditioning will be required increasingly more in profoundly populated urban zones. The three bottom-line principles of sustainability namely, economic, environment and social is significant in considering the sustainability of air-conditioning systems; however, the real issue confronting mankind with respect to the three bottom line principles of sustainability is whether human action is sustainable. For this paper, the assessment of renewable smart air-conditioning is regarded as sustainable if:

- the system considers the three pillars of sustainability namely; environment, economic and social respectively as a whole and, or 
- the most efficient means for re-establishing the system to sustainability may necessitate change in the system. In other words, combining both the renewable and smart/ intelligent system as a unique system for the sustainability of the system which in turn improves the human adaptation of the wellbeing of occupants.

Renewable smart air-conditioning can be defined as a sustainable innovative system that uses renewable energy and intelligent control procedures to optimize the quality of indoor air environment, lower the levels of energy consumption and rate of carbon emissions which in turn combats global warming and climate change. Moreover, Gugulothu et al., (2015) suggested that structures are accountable for the utilization of around forty percent of the essential energy and the outflow of about thirty-three percent of greenhouse gases on the planet. Similarly, established researchers have committed a lot of exertion to secure housing energy sustainability in two primary ways; those utilizing renewable energy for the remaining and those lessening outside energy supply. In the two different ways, resources of solar assets are picking-up acceptance since they increase energy autonomy and sustainability simultaneously while contributing almost zero effect on the environment. Subsequently, lessening the degree of energy utilization and guaranteeing ideal level of comfort in designing a smart air-conditioning system contributes considerably to the level of absolute energy utilization. Several research studies recommended that areas like assembly rooms, indoor arenas and meeting lobbies contribute as much as seventy five percent of the overall energy consumption related with air-conditioning utilization. However, Wang et al., (2012), proposed that decrease of energy utilization, waste in structures and $\mathrm{CO}_{2}$ requires an intelligent control system for the reason that energy utilization has been legitimately connected with wellbeing and eventually to operational expenses. A structure's indoor environmental essential factors of comfort, as indicated by the users' inclinations are indoor air quality, visual and thermal (Siddqui et al., 2015). Thusly, studies have demonstrated that intelligent fuzzy logic model produced promising outcomes and is applied to a considerable case in structures while showing broad overall energy utilization decrease and decline of $\mathrm{CO}_{2}$ as opposed to the current control system and accomplishing the level of ideal comfort (Wang et al., 2012; Siddqui et al., 2015; Yu and Lin, 2015). In this manner, controlling systems designers have been taking a step at creating different control methodologies for air-conditioning systems so as to optimize the air-conditioning exhibition. Studies uncovered that indoor structure environments control systems can be mostly characterized into two classifications as per the methodologies utilized: computational intelligent procedures and conventional controllers. The proportional integral derivative controller is one of the most well-known air-conditioning systems customary controllers. Neural networks, intelligent controller have as of late turned out to be applied as a flexible, accurate and fast device to the control methodology design, modelling and simulation of air-conditioning. Through an appropriate structured controller, the exhibition of an air-conditioning system can be altogether improved. Then, it merits creating sustainable-based novel control techniques to optimize the energy efficiency and indoor environment quality for renewable air-conditioning system.

Consequently, Oye et al., (2020), suggested that all project such as the renewable air-conditioning ought to earn profits over a long period of time that is enough to develop and 
survive. The living standard improvement and national income is the index to the system economic progress. For this reason, profit is the legitimate purpose of the system; even so, it must not remain fundamentally over-emphasized. Possessors of the system may attempt to make best use of the project profit considering the society welfare. Hence, revenue is not just the return to possessors; however, it is likewise associated with the interest of the society other sectors. Profit is the measure for arbitrating not only for the economic sustainability, but likewise the social purposes, management and efficiency of the system (Oye et al., 2020).

In the mission for climate change mitigation, for instance utilizing renewable energy sources, especially generation of solar energy to power smart air-conditioning to exterminate various indoor health effects and reduce the level of energy consumption and carbon emissions are expected to produce sustainable future developments zones further climate resilient. Therefore, this paper compliments existing research in sustainability domain by reporting the theoretical assessment of air-conditioning system through applying the bottom-line principles of sustainability. The proposed theoretical framework of renewable smart air-conditioning rationally contributes to the industry, renewable energy and sustainability studies through offering solar energy, smart technologies and profitability measures as a reasonable answer towards the fundamentals of sustainability for air-conditioning.

\section{Conceptual Issues of Sustainability}

Currently, societies and humankind face sustainability challenges which primarily connects with the capacity to sustain ecosystems, humanity, and societies on the planet. In the future, these challenges are anticipated to turn out to be more substantial. Accomplishing sustainability in the aspect of air-conditioning is consequently one of the most vital objectives of a society and its people since air-conditioning has generally been applied as a result of the improvement in the way of life.

The concerns and issues personified through sustainability are comprehensive and many. They subsequently cover such various issues as pollution and climate change, government policies, stability and peace, anthropogenic and natural disasters, social and cultural sustainability, globalization, urbanization, population growth, energy consumption, carbon emissions, indoor air quality, energy efficiency, industrial development, production, technological systems such as smart/ intelligent control systems, ecosystem degradation, drought and water quality, loss of biodiversity and species extinction, desertification and land use, sanitation, resource supply (food, mineral, energy, water) and waste management (conventional, radioactive, hazardous toxic). However, the extensiveness of matters associated to sustainability proposes that a comprehensive and holistic tactic to sustainability is required. Sustainability actions are progressively becoming the businesses and governments agendas and operating strategies. The sustainability principles (environment, economic and social) are required to be associated if actions are to achieve the fundamental goals of sustainability for renewable smart air-conditioning.

\section{Sustainable Framework Assessment}

The sustainability assessment framework is significant for making sustainability functioning, 
monitoring and measuring the progress of renewable smart air-conditioning. Nevertheless, assessing sustainability is challenging, because there is no generally recognized sustainability technique that exists for a system. There are several motives for this, as well as the arduously in quantifying the key pillars of sustainability (Hacatoglu et al., 2016). For instance, albeit ozone depleting substances and greenhouse gases emissions are quantifiable, measuring their social and economic influences is challenging. Likewise, regardless of living standard frequently being quantified as 'gross domestic product per capita'; life quality can be further important measure of satisfaction, comfort and human well-being. In this regards, assessment of sustainability can also be argumentative (Morse and Fraser, 2005). However, several approaches for measuring or assessing sustainability have been established as discussed below:

- A number of methods of assessment apply indicators or principles of sustainability, which are characteristically straightforward quantitative substitutions that systematically measure environmental, social and economic factors. The indicators of sustainability are typically integrated, unifying the bottom-line principles namely social environment and economic whereas, others are not integrated, quantifying only a single sustainability fragment. This method unifying the three bottom-line principles is analytically proposed in this paper as a result of its suitability and straightforward measuring proxies for the renewable smart air-conditioning.

- Indexes of sustainability have been established grounded upon a composite or aggregate of certain indicators of sustainability. A single-value sustainability quantity grounded upon an aggregate index is valuable for communication and understanding, owing to its straightforwardness. Nevertheless, the resolve of such indicators requires aggregation, weighting and normalization of data. These stages generally lead to a loss of beneficial information and can be problematic. The measure of a single-value sustainability can cover facts that are essentially connected with the multidimensional nature of sustainability and therefore be deceptive. As a result of this known facts, such quantifying method for the framework sustainability assessment of the renewable smart air-conditioning system is not recommended.

- Research studies by Daly (1990), established sustainable development operational principles. Albeit beneficial, these are restricted to quasi-sustainable use of non-renewable resources and as result, this method is not suggested in this paper due to their limited usage.

Studies unfolded that a small number of sustainability assessment approaches simultaneously reflect the three bottom-line principles of sustainability namely economic, environment and social. Conversely, several methodology assessments lay emphasis upon only one sustainability area or dimension such as the environment or economic sustainability. Numerous instances are contemplated to demonstrate this as highlighted below:

- Assessment of biophysical methods is suitable for assessing environmental sustainability, through measuring environmental impact and resource use. Nevertheless, they are usually inappropriate for addressing economic and social domains of sustainability. 
- Financial assessment can be applied to environmental and social capital to evaluate sustainability. Nevertheless, financial assessments for non-market services and goods are not well established, inappropriate appraisals, and problematic owing to our restricted ecosystems understanding and the resources they offer.

- The index of environmental sustainability positions countries grounded upon numerous environmental indicators aggregate. Nonetheless, these are generally incapable to associate economic growth and environmental sustainability.

Table 1. Applications of Sustainable Framework

\begin{tabular}{|l|l|}
\hline Authors and Year & Applications of Sustainable Framework \\
\hline Sustainability of technology & Sustainability of technology via a range of illustrations \\
\hline Dewulf et al., (2000) & Sustainability indicators for renewable energy \\
\hline Sustainability of energy & $\begin{array}{l}\text { Sustainability of a national energy conversion } \\
\text { system using hydrogen from solid fuels }\end{array}$ \\
\hline Evans et al., (2009) & $\begin{array}{l}\text { Global energy assessment for } \\
\text { sustainable routes identification }\end{array}$ \\
\hline Gnanapragasam et al., (2011) & Gomez-Echeverri et al., (2012) \\
\hline Sustainability of manufacturing operations \\
\hline Nazzal et al., (2013) & Sustainability as a tool for manufacturing decision making \\
\hline Sustainability of infrastructure and buildings \\
\hline Khalid et al., (2015) & $\begin{array}{l}\text { Sustainable building of heating, } \\
\text { ventilation, and air-conditioning }\end{array}$ \\
\hline Russell-Smith et al., (2015) & Sustainable target value design to improve buildings \\
\hline Sustainability of energy, water and environment systems \\
\hline Krajacic et al., (2015, 2018) & $\begin{array}{l}\text { Sustainability overview of the topic and } \\
\text { description of sample studies }\end{array}$ \\
\hline Sustainability of region & Sustainability for the world \\
\hline Gomez-Echeverri et al., (2012) & Sustainability for countries \\
\hline Gnanapragasam et al., (2011) & Sustainability for state \\
\hline Mansoori et al., (2016) & Sustainability for suburbs \\
\hline Oye T. T., (2018)
\end{tabular}

The non-existence of a framework approach is the weakness of numerous existing approaches of assessing sustainability, which considers the system being measured as a whole and typically accounts for the connections amongst its subsystems. This is significant for the reason that attaining a society that is sustainable is a systems problem, where the economic, social and environment are completely interdependent. Integrated human-environmental systems have connections between diverse systems that basically lead to trade-offs; for example, costs reduction can perhaps originate a procedure to have lower efficiency or higher emissions. An approach of non-systems concentrating upon solitary factors can perhaps be regularly understood to be insufficient for holistically assessing sustainability. As earlier noted, for instance, biophysical methods lay emphasis primarily upon environmental 


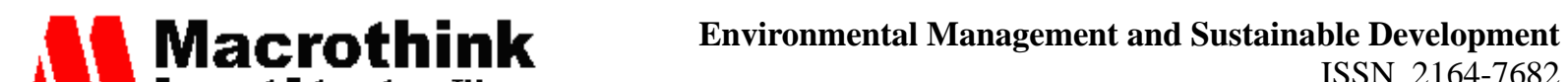 Institute"

sustainability and disregard social and economic dimensions, whereas approaches grounded upon weak sustainability typically lay emphasis upon factors of the economic and disregard the biophysical sustainability domain. Obviously, a system sustainability requires to be assessed with a systems framework method. Analysis of life cycle is generally a fragment of such method, as it recognizes the system energy and material inputs and outputs or procedure and utilizes this information to assess the effects of economic, social and environmental domain of the system framework. In the light this, the sustainability principles via a sustainable framework concept can be systematically applied for renewable smart air-conditioning with the purpose to reduce the level of energy consumption and rates of carbon emissions while improving the system control performance and inhabitants' comfort. Nevertheless, in recent years, the principles of sustainability using framework concept have been applied to some areas as given in Table 1.

\section{Proposed System framework Using Sustainability Principles}

Consequently, Figure 1 systematically offers and applied the three pillars of sustainability namely; environment, economic and social as a whole arising from the methodical framework and subsequently re-established the system to sustainability which necessitate transformation in the system. In other words, it combines both the renewable and smart system as a unique system for the sustainability of the system which in turn improves the human adaptation of the wellbeing of occupants. 


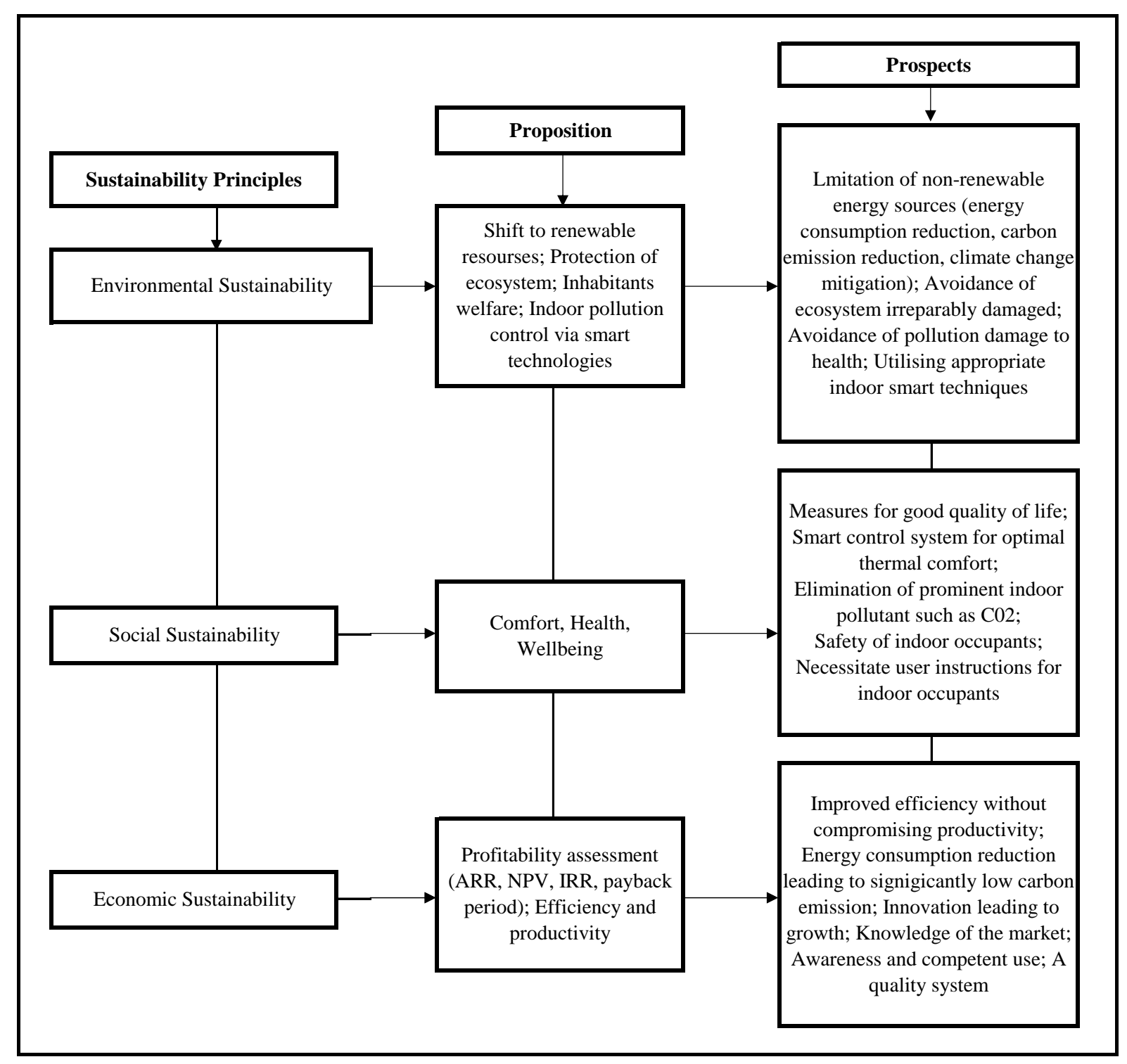

Figure 1. Proposed framework using sustainability principles and indicators

The environmental sustainability requires economic sustainability, and social sustainability relies on environmental sustainability. On the other hand, the three areas of sustainability can be treated with equality as proposed by research studies. The promotion of sustainable practices is to typically pursue a balance between environment, economic and social performance in project applications. That is to say, the connection amongst sustainability, renewable energy and smart control for air-conditioning becomes clear to reduce the level of energy consumption and rates of carbon emissions while tackling health effects of inhabitants. In this regard, Figure 2 takes the proposed indicators of sustainability further to systematically present a sustainability framework for renewable smart air-conditioning. 


\section{Macrothink}

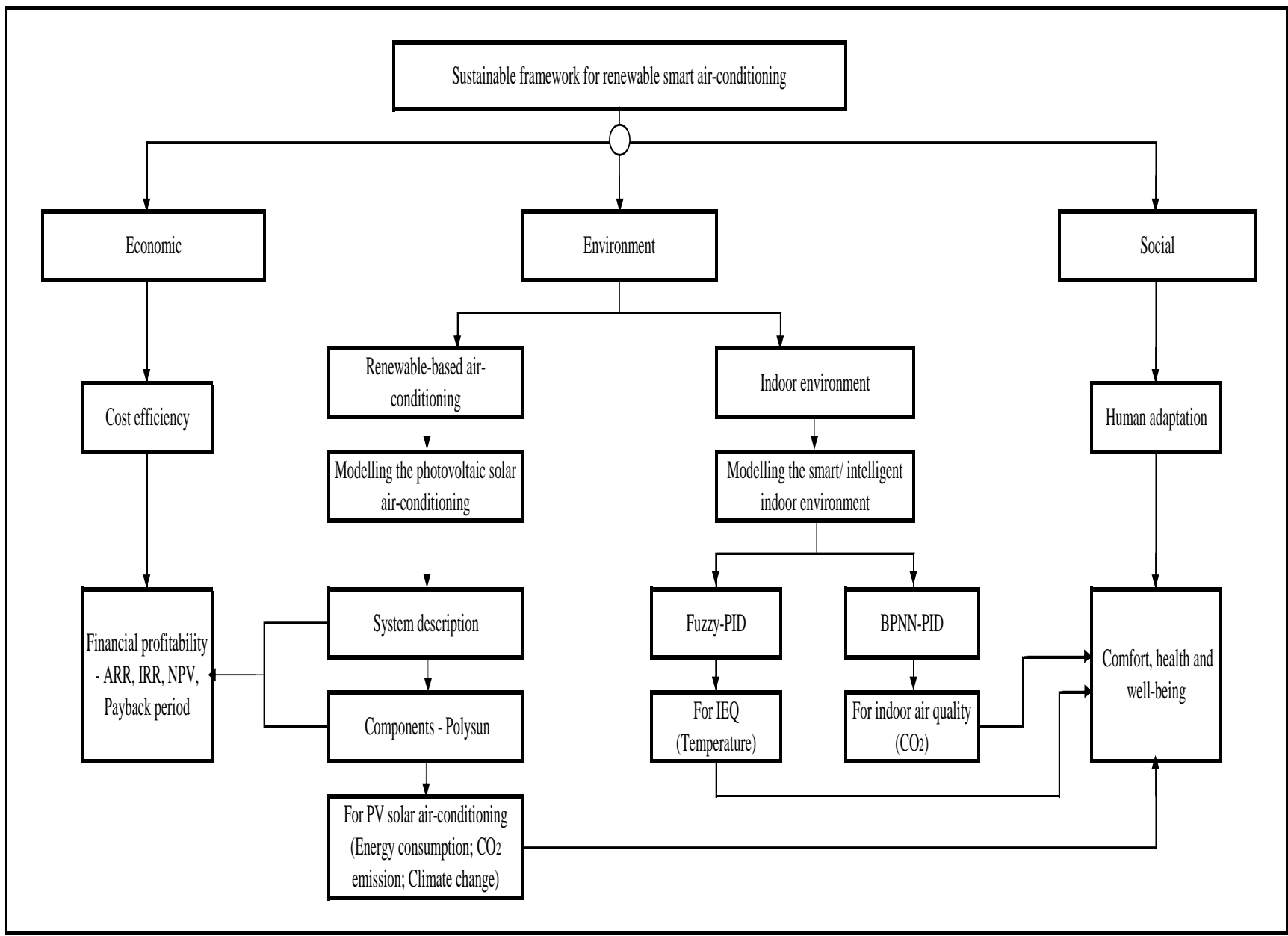

Figure 2. Sustainable framework for renewable smart air-conditioning

Accordingly, Figure 2 set out the theoretical sustainable framework for renewable smart air-conditioning. This analytical grid is subsequently augmented by the three pillars of sustainability namely environment, social and economic which in turn unfolds the basis of sustainable smart air-conditioning in this paper. Here, the theoretical framework of the proposed system is thoroughly designed by way of the adaptation strategy of the three bottom line principles of sustainability where the environment is technically influenced by both the social and economic sustainability. Therefore, moving from top-to-bottom, this in turn indicates two forms of sustainable environment for sustainable-based smart air-conditioning namely, renewable air-conditioning and the indoor environment. The renewable-based air-conditioning unfurled the conceptual modelling approach for the system description of the photovoltaic solar air-conditioning while the mathematical modelling of the indoor environment unleashes two forms of smart/ intelligent indoor environment namely, fuzzy logic control - proportional integral derivative (FLC-PID) and back propagation neural network - proportional integral derivative (BPNN-PID) for the manageability of both indoor temperature and indoor $\mathrm{CO}_{2}$ respectively. Here, particular attention is drawn to the connection of both the environment and social sustainability of the system where the PV solar air-conditioning (energy consumption, $\mathrm{CO}_{2}$ emissions and climate change), IEQ (temperature) 
and the indoor air quality $\left(\mathrm{CO}_{2}\right)$ is in turn horizontally linked to the wellbeing and comfort of the inhabitants or users of the building through human adaptation. Moving horizontally, particular attention is also drawn to the connection of both the environment and the economic sustainability of the system where the depicted system and components unfurled the financial profitability of the system namely, net present value, internal rate of return, accounting rate of return and payback period through the cost efficiency of the proposed theoretical framework. Therefore, the principles of sustainability namely, environment, economic and social aimed for renewable smart air-conditioning are systematically addressed in the following sections.

\subsection{The Environment}

The subsystems of the environment are social and economic which is the basis and descend of the Earth entire energy and material interactions. The sustainability of humankind suggests guaranteeing the Earth ability to underpin the associated human and activities. Inhabitants and human economies have developed such that activities of anthropogenic currently have long-term and global effects, with numerous consequences. These can reduce the planet capacity to fundamentally sustain life. However, numerous environmental issues influence sustainability such as the energy consumption and carbon emissions emanating from the use of air-conditioning systems around the world causing climate change and health effects on inhabitants. There is also loss of biodiversity all over the biosphere, owing to economic growth and other related factors as a result of the constant usage of air-conditioning system during the hottest period of the year, and this subsequently put threats on environmental sustainability. Therefore, the conceptual modelling and mechanisms of solar air-conditioning to reduce the level of energy consumption and rate of carbon emissions is unfolded in the next subsection.

\subsubsection{Conceptual Modelling and Mechanisms of Solar Air-Conditioning}

The adapted building is a household located in Rome, Italy. The chosen location is as a result of the hot temperate environment. Subsequently, $500 \mathrm{kj} / \mathrm{K} / \mathrm{m}^{2}$ is the capacity of heat and $0.5 \mathrm{~W} / \mathrm{K} . \mathrm{m}^{2}$ is the proposed building coefficient total heat loss that basically commensurate with a regular insulated light of building construction. The key mechanisms of the photovoltaic solar air-conditioning are the modules of photovoltaic associated with an alternating/ direct current inverter, outdoor heat rejection unit, indoor cold distribution elements and electric-driven chiller. The modelling of the system comprises of the outdoor unit for warming the domestic hot water, the cold storage, and a hot storage. Figure 3 represents the photovoltaic panel arrangement which is situated on the roof of the building. 


\section{MInstitute Macrothink $^{\text {Int }}$}

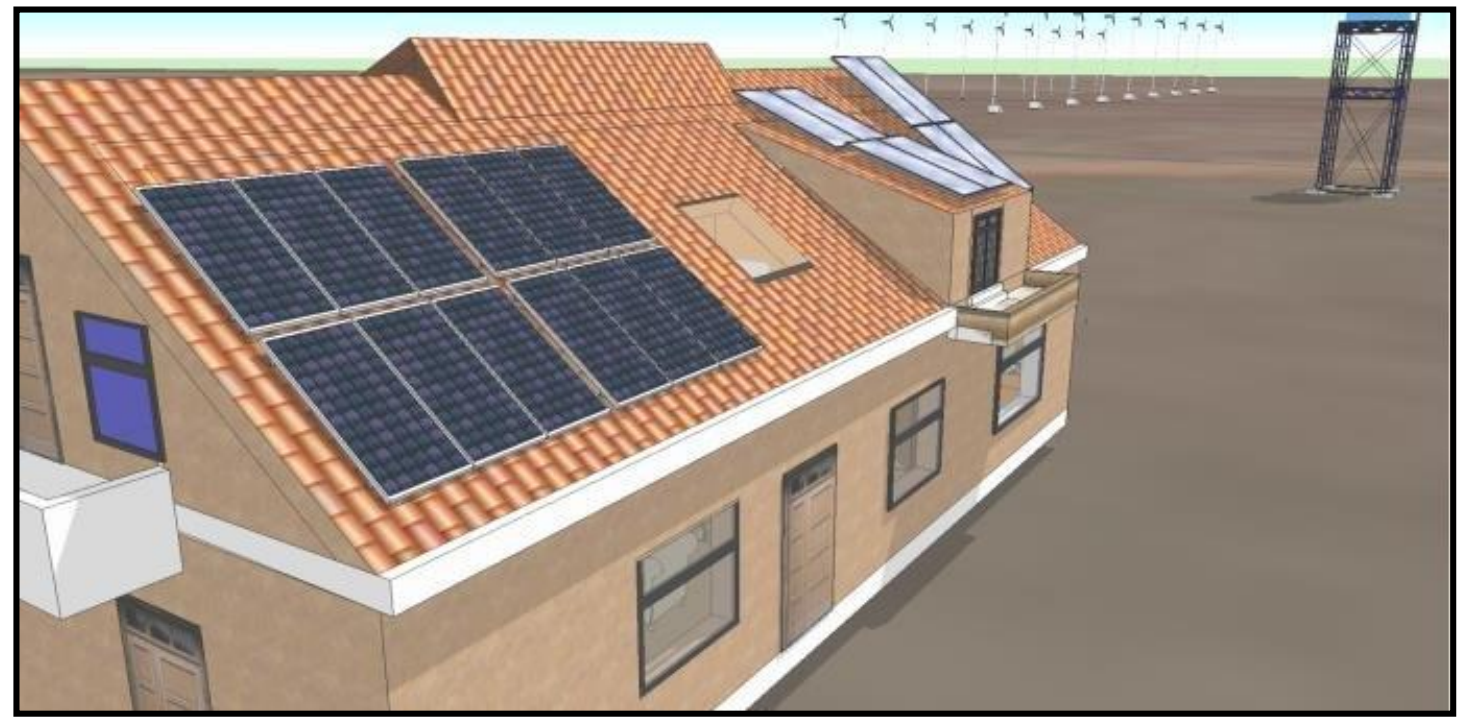

Figure 3. Scenario-based photovoltaic panel arrangement

The silicon monocrystalline photovoltaic cells absorb power from the solar and convert it to electrical energy. The cells efficiency is $17.4 \%$ and each element size is $1.65 \mathrm{~m}^{2}$. The photovoltaic frameless elements are protected through solar glass of $5 \mathrm{~mm}$ having coating antireflection with the $9 \mathrm{~mm}$ overall width. For $14.77 \mathrm{~m}^{2}$ is the overall zone of nine installed photovoltaic components. Also, $285 \mathrm{kWp}$ is the extreme irradiation of minimal power of individual photovoltaic component, having $\pm 3 \%$ error. Likewise, $2.565 \mathrm{kWp}$ is the extreme irradiation of minimal ultimate entire photovoltaic array power. It matches to the $2.5 \mathrm{~kW}$ which is the cooling machine of extreme electrical power. Equally, $31.2 \mathrm{~V}$ is the current photovoltaic extreme power point component with $38.3 \mathrm{~V}$ as the voltage open circuit. For $8.7 \mathrm{~A}$ is the current of photovoltaic component and subsequently, 9.2A is the current short-circuit.

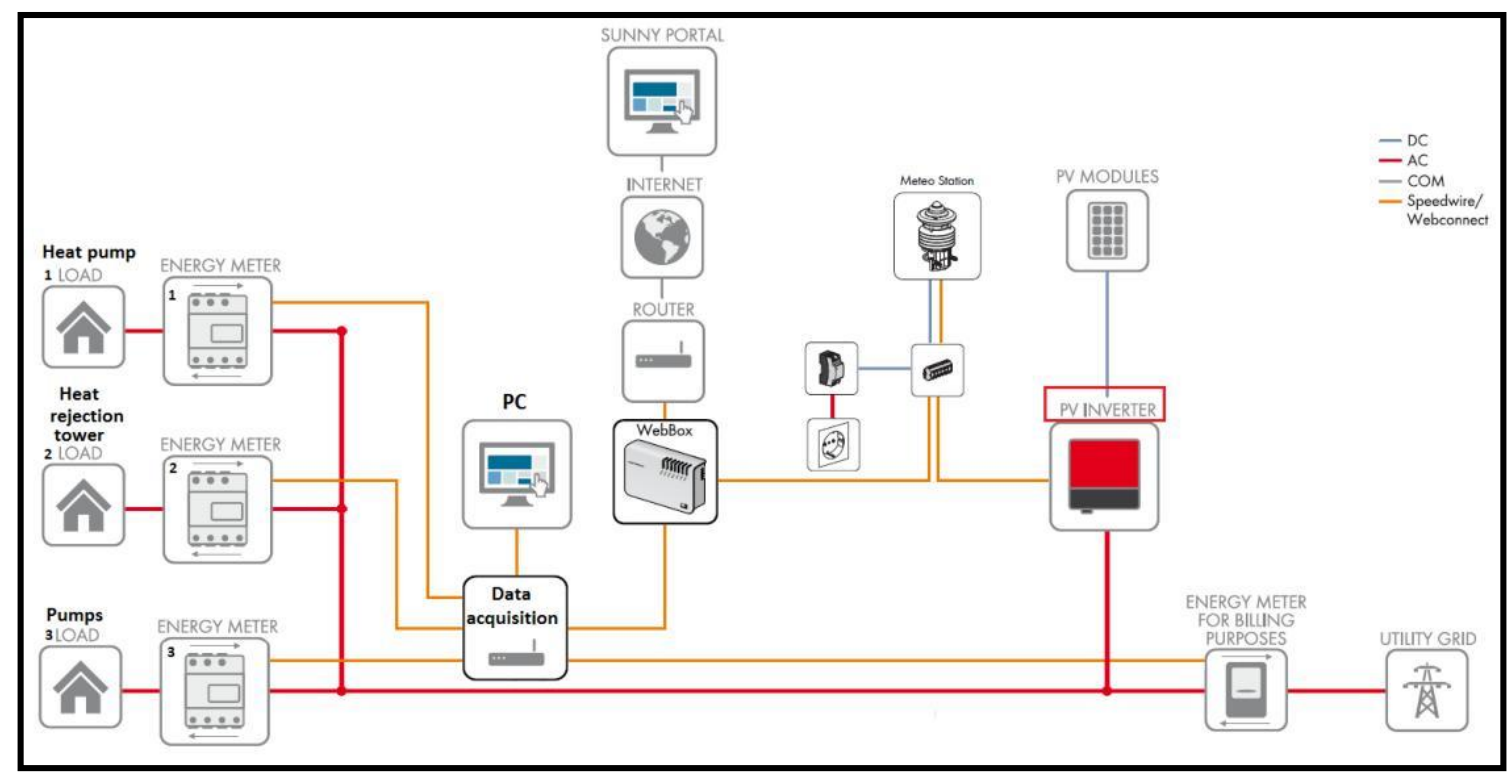

Figure 4. Model representation of integrated photovoltaic electrical network components 
Also, the over-current shield is $18 \mathrm{~A}$ which is in-parallel and the entirely photovoltaic components are connected electrically. For $280.8 \mathrm{~V}$ is the entire voltage and $1000 \mathrm{~V}$ is the extreme voltage system range. Photovoltaic components connection through the manufacturers' recommendation is sixty at serial connection maximum number. Manufacturer representative guarantees the categories of these photovoltaic units; however, there is lowest of ninety percent performance after ten years of usage and eighty percent after twenty-five years. Hence, in the calculations, photovoltaic minimal power reduction with time is considered. Likewise, $0.9 \%$ is the yearly efficiency reduction of the preceding annual's rate. Hereafter, the photovoltaic units unframed are aimed to be secured on the proposed roof area. For $15^{\circ}$ inclination to horizon are advised for photovoltaic units to be ascended. The roof examined is with a slope of $5^{\circ}$. This suffices angle aimed at connection of electric power beneath the elements. Aluminum is examined for sketching unframed components. The ascending of photovoltaic considered is designed in understanding of flexion defense with likely alterations owing to enlargement of the thermal. Flexion defense from uppermost and lowermost is planned concerning snow masses and winds respectively. Rubber gaskets amongst the mounting and photovoltaic elements are examined to permit expansion of the thermal alterations.

\subsubsection{System Process of Operation}

The proposed operation of the solar air-conditioning is improved through various subsystems and the precedence in a cooling season is covering the cooling mandate. The cooling machine to the heat pump is examined to offer heat transfer from the environment of low temperature to an environment of high temperature. The heat pump is power mutable and is regulated through its peculiar regulator box. The heat rejection to the hot storage is measured through the uppermost potential of heat rejection. The temperature of the water at the tank middle level and the internal coil of the coefficient heat transfer are demarcated in order to administer this potential concerning hot storage. Also, the heat transfer rate of outdoor unit, the air temperature of outdoor and the consumption of electricity of the fan is reproduced through the main energy factor.

Nevertheless, free or unrestricted heat rejection of the hot storage is considered during the conceptual modelling of the photovoltaic solar air-conditioning. Unrestricted heat rejection emanating from hot storage in the direction of the outside air through the operation of outside unit is without the operation of heat pump. There is consumption of electricity in this procedure with consumers being the hot-side pump and outside fan component. As a result, the unrestricted heat rejection is detached from the operation of the system in acquiescence with outcomes of the pre-simulation. The regulator obliges for domestic hot water preheating in the non-cooling season. In this circumstance, some mechanisms of the system operate in the reverse mode, for instance, the outside component is a source of heat, and its interrelation is subsequently substituted to the cold side of the heat pump. The purpose of this regulator is to extremely protect the thermal energy mandate of the domestic hot water. The foremost obstacle at this juncture in non-cooling season is a low temperature of the outside air. For the outdoor unit, this primarily causes unsafe freezing. Also, the low temperature of the outside air subsequently upsurges the difference in temperature in both the hot and cold side of heat 
pump. This expressively reduces the coefficient of performance of the heat pump and can brand the system less appealing.

For the flow and return hot side temperatures, heat pump is regulated through the integral sensors. Temperatures of the brine return may be restricted if needed to the lowest. Also, regulator of the production of heat may be examined in dual conducts. The heating of domestic heat water management is achieved grounded upon the principle of "float condensing" - meaning the level of temperature required for heating at a precise temperature of the outdoor is formed and directed via accumulated values emanating from outside and the flow sensors. The sensor of the room temperature can likewise be examined to reimburse the nonconformity in room temperature (Cooling Machine Manufactory, 2019). The heat pump transports the heat up to a secure level of temperature in the other regulator technique and it is recognized as "fixed condensing". The mechanized system of the heating operation is then substituted through the device of outside regulator unit. Therefore, the essential representation of the system through polysun software program is revealed below in Figure 5.

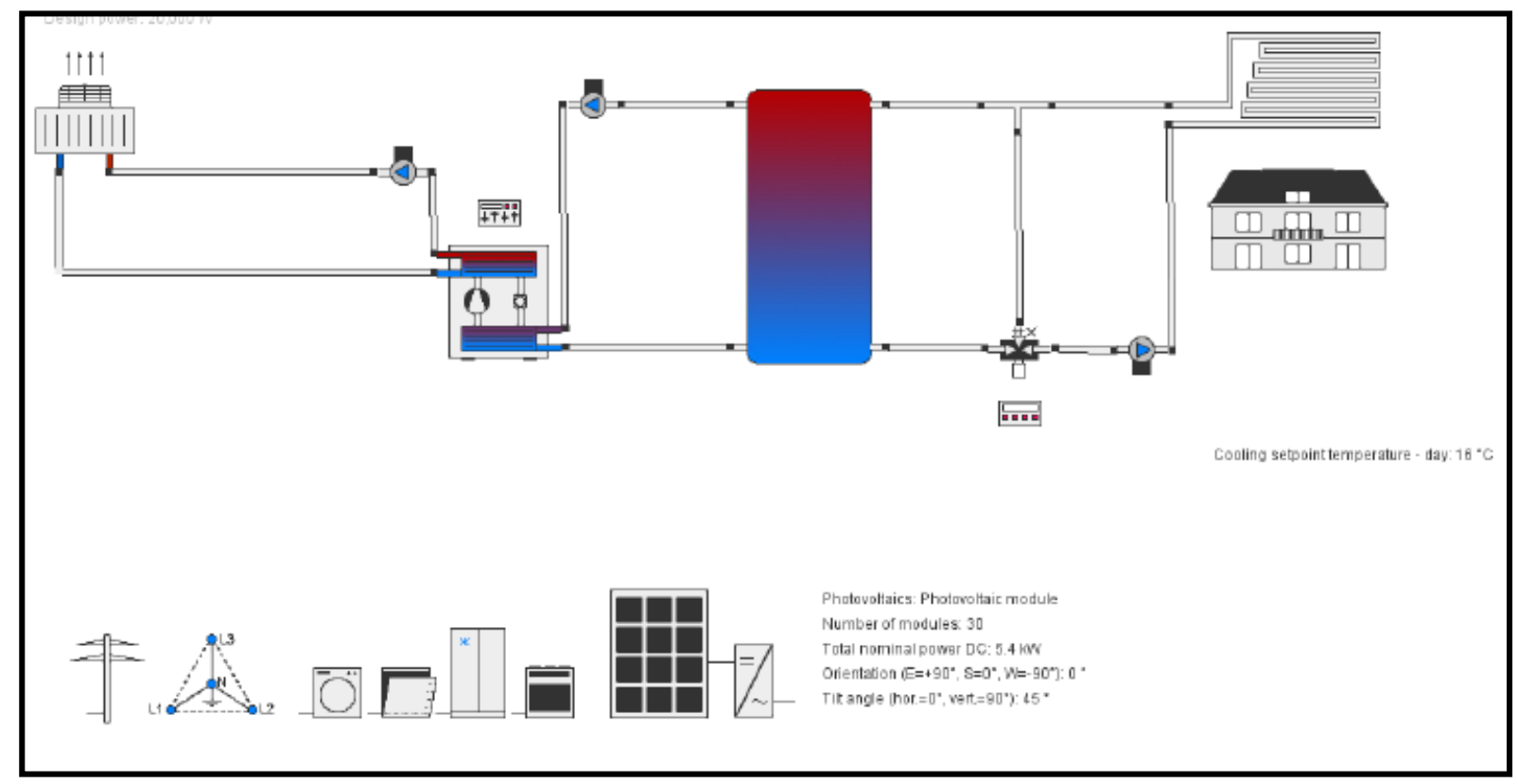

Figure 5. Essential representation of the solar air-conditioning

\subsubsection{Conceptual Improvement of the System}

Accordingly, the improvement performance of the system through including sub-system were theoretically explored in this paper for London, Toulouse and Rome districts. Research studies by Mauthner and Weiss (2014), suggested that majority of the solar air-conditionings are situated in specific European districts due to their climatic conditions. Hence, examinations were constraints to the above-mentioned three locations within the EU. This is associated with their impact on the general performance of the system - the necessity is that the cooling request must be covered. The supplementary components of the system can be added till satisfactory improvement is achieved. Thusly, the system without augmentation has fewer segments, which essentially improves the innovation. Through the cold demand, the cooling machine generates cold that is hard to gauge. Therefore, surpassing the cold production and 
henceforth power utilization can occur. For the system cooling limit in this circumstance is deficient, and the building set temperature is not gotten. Therefore, the cooling machine power is expanded on account of the subsystem. Moreover, Table 2 presented the annual improvement performance result for the three districts.

Table 2. Annual system improvement performance results

\begin{tabular}{|l|l|l|l|l|}
\hline System & Unit & London & Toulouse & Rome \\
\hline System Performance & - & 3.97 & 3.64 & 3.45 \\
\hline Self-consumption & $\mathrm{kWh}$ & 4651.9 & 6315.9 & 6468.5 \\
\hline Yield of PV AC & $\mathrm{kWh}$ & 824 & 1448 & 2010 \\
\hline To external grid & $\mathrm{kWh}$ & 3828 & 4868 & 4458 \\
\hline From external grid & $\mathrm{kWh}$ & 1377 & 1918 & 3119 \\
\hline Heat generator energy to the system & $\mathrm{kWh}$ & 10976 & 15556 & 22749 \\
\hline Total energy consumption & $\mathrm{kWh}$ & 8675 & 12176 & 17658 \\
\hline Energy deficit & $\mathrm{kWh}$ & 1361 & 3490 & 6235 \\
\hline Total fuel and/ or electricity consumption & $\mathrm{kWh}$ & -2465.2 & -2967.4 & -1357.5 \\
\hline Total electricity consumption & $\mathrm{kWh}$ & 2201 & 3366 & 5130 \\
\hline Primary energy factor & $\mathrm{kWh}$ & 0.28 & 0.28 & 0.32 \\
\hline Degree of self-sufficiency & $\%$ & 37.4 & 43 & 39.2 \\
\hline $\mathrm{CO}_{2}$ Savings & $\mathrm{kg}$ & 2495 & 3388 & 3470 \\
\hline
\end{tabular}

Correspondently, the key focus of the execution of the cold storage for the three districts is to diminish the demand of electricity peak. In this way, if the system in view is updated basically with a cold storage, the room temperature variances may be extensively diminished by way of affecting the pinnacle load. In the solar air-conditioning, the cold storage obliges to overcome any issues between the cooling request and solar power gain. The cooling machine activity is nearer to the ideal driving temperature array with the inclusion of a cold storage tank, which marginally expands the heat pump regular productivity. Additionally, because of this expansion with the present cooling load of each district, the activity time for generation of cooling could be decreased. Also, the heat rejection usage through preheating of the domestic hot water recycles in excess of a fourth of the heat rejected. Albeit, to protect the cooling request in times of low radiation of solar, the strategy of free cooling may be connected if the temperatures of the open-air are in a range that is suitable. This present system performance permits a productive cooling request covering. Also, the energy flow diagram presented in Figure 6, Figure 7 and Figure 8 subsequently shows that there is effective cooling request for the three locations. It significantly demonstrates that the proposed system is self-sufficient and able to produce the required energy demand throughout the year. 


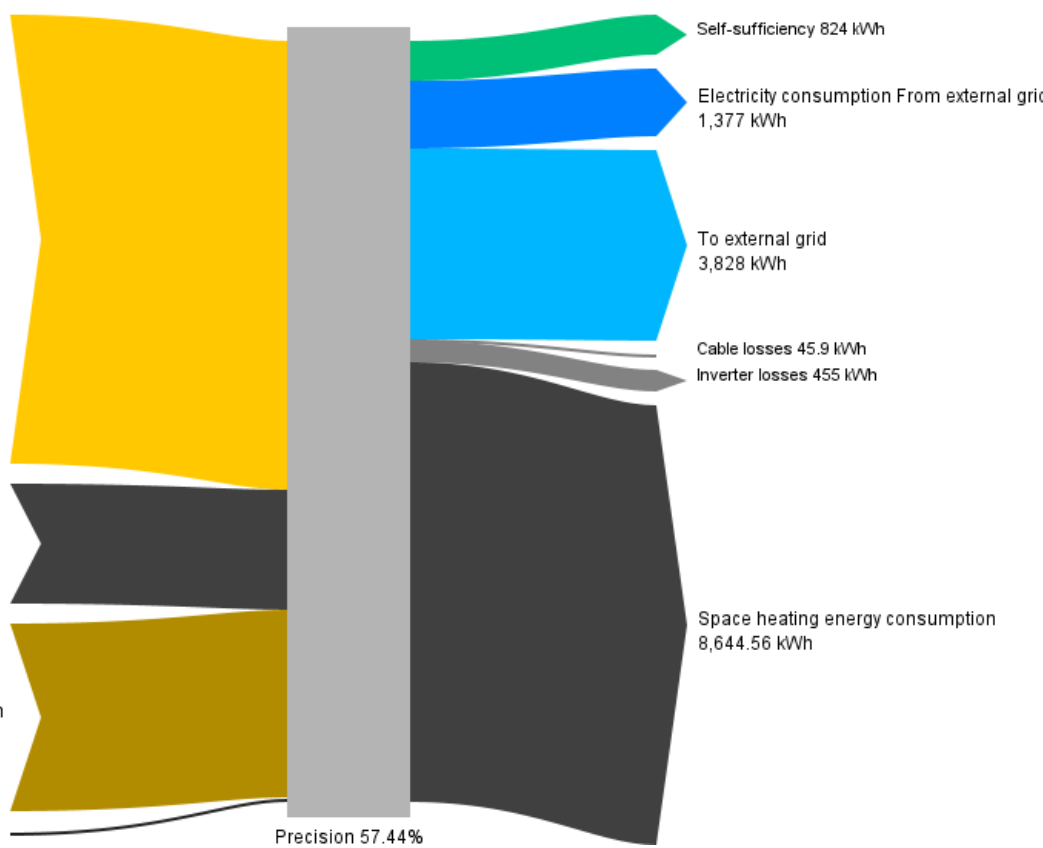

Figure 6. Energy flow diagram - London district

Yield Photovoltaics DC $6,942.9 \mathrm{kWh}$

From external grid $1,918 \mathrm{kWh}$

$B N$ or WN heat pump Cooling: Electricity consumption $3,328 \mathrm{kWh}$

Electricity consumption of pumps $20.9 \mathrm{kWh}$

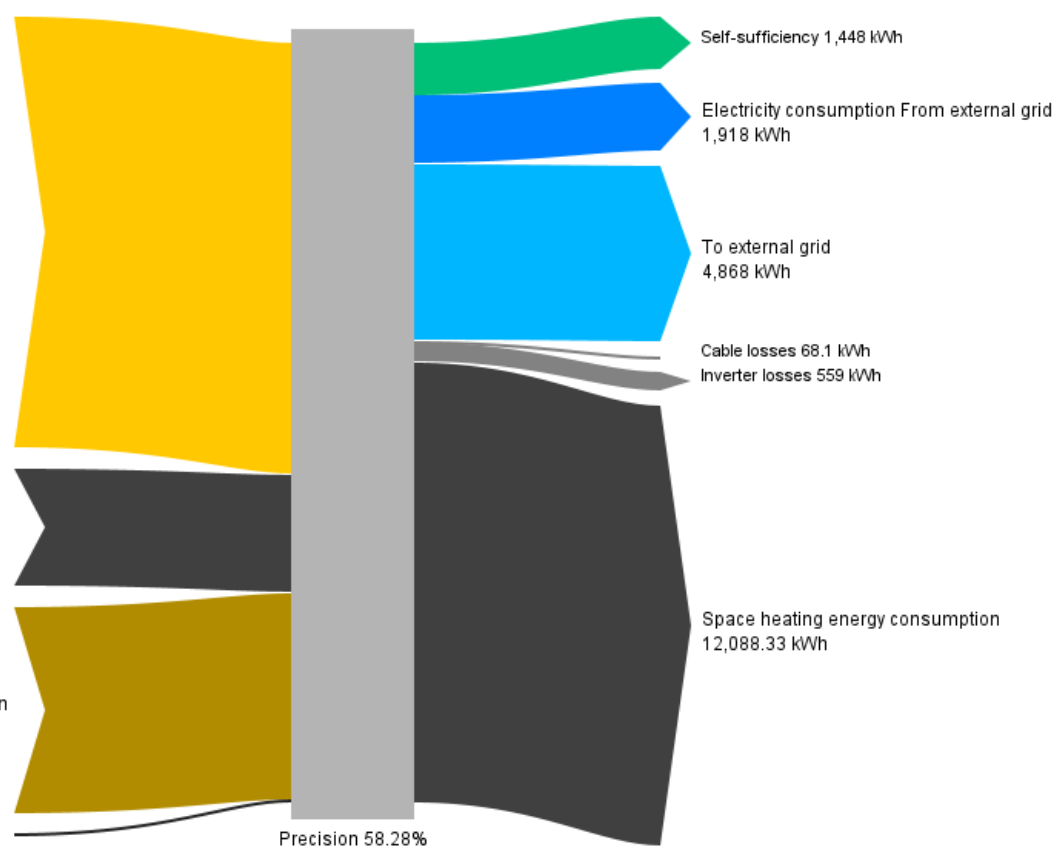

Figure 7. Energy flow diagram - Toulouse district 


\section{MlMacrothink}

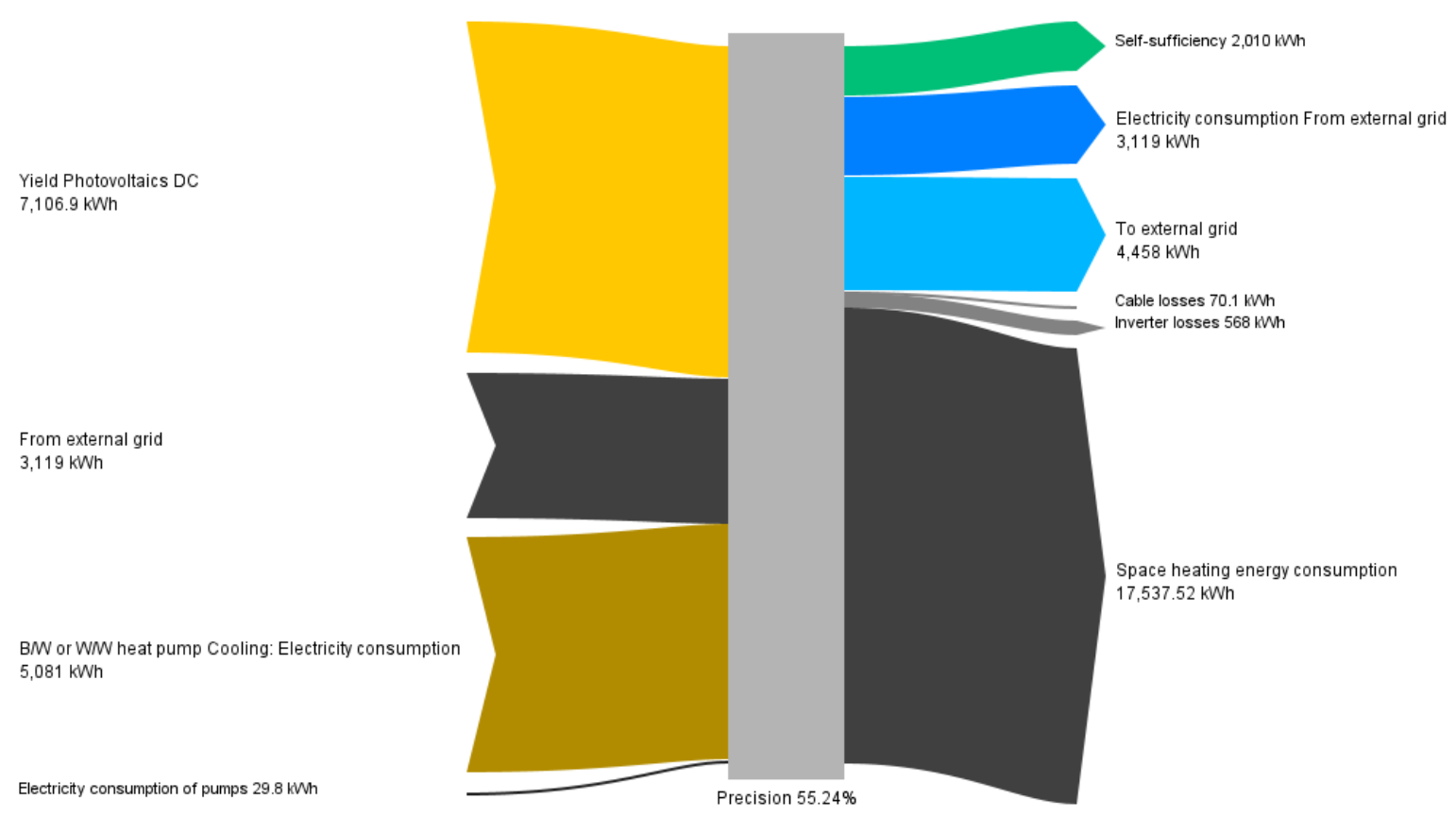

Figure 8. Energy flow diagram - Rome district

Also, the cooling machine outdoor unit is utilized in the non-cooling season as warmth hotspot for preheating of domestic hot water. In most cases, the building cooling request is influenced through its envelope protection, via the proportion of window-to-divider zone just as through the measure of interior load, infiltration and ordinary ventilation. In the cooling season, the utilization of resources with lesser thermal conductivity implies higher costs of investments and may prompt higher cooling energy requirements. Nonetheless, thermal improvement builds the demand of the yearly cooling. Hence, there is decrease in the level of energy consumption which leads to significant amount of $\mathrm{CO}_{2}$ savings in each district as presented in Table 2. However, the results show that photovoltaic solar air-conditioning innovation can cover the cooling request in the proposed locations while reducing the level of energy consumption and the rates of carbon emissions. However, the climate change which is the utmost key significant challenges of sustainable environment emanating as a result of the rate of energy consumption and carbon emissions is likewise discussed below:

Climate change: Steadiness of the greenhouse gases (GHGs) concentrations in the atmosphere; for the reason to avert the damaging consequences of climate change and global warming is established by most investigations as the significant challenges of the present-day. The greenhouse gases consume infrared radiation released at the Earth surface in the atmosphere. This subsequently leads to the effect of greenhouse and the related terrestrial warming. The main greenhouse gas is carbon dioxide $\left(\mathrm{CO}_{2}\right)$, nevertheless there are other greenhouse gases such as nitrous oxide $\left(\mathrm{N}_{2} \mathrm{O}\right)$ and methane $\left(\mathrm{CH}_{4}\right)$. The foremost anthropogenic origins of greenhouse gas emissions consist of the combustion of fossil fuel, ruminant animals' enteric fermentation and utilization of agricultural nitrogen. Global warming and climate destabilization risks are worsened through effects of positive response, for instance, the growth of absorption solar radiation occurring as a result of the loss of reflecting exteriors like ice. Since 1990, the Intergovernmental Panel on Climate Change 
(IPCC) published an inclusive report assessment revising the state-of-the-art climate science and forecasts trends of the future. In 2014, the finalized fifth reports assessment unfolded the warming trends because of anthropogenic actions as "very likely". Studies by Berthiaume and Rosen (2017), proposed that the amount of projected warming has subsequently intensified as climate models turn out to be further sophisticated, and as a consequence of the associated climate and supplementary influences. Considerable attempt at the United Nations and universally is concentrated upon attaining world-wide treaties or agreements to stabilize concentrations of the greenhouse gas in the air at a level that evades unsafe anthropogenic climate change. As a result of this movement, this paper unfolded the use of renewable energy for air-conditioning which in turn contributed to such goals by means of diminishing the system level of energy consumption and rate of carbon emissions.

\subsection{The Social}

Social sustainability is a comprehensive notion such as cultural development, wellbeing, health, equity and several other factors. A specific meaning of social sustainability and its contribution is ongoing universally. The development of sustainability rational to comprise a strong social constituent took some time. Initial effort on sustainability is usually concentrated upon either economic sustainability or environmental sustainability while neglecting the social sustainability factors. The importance of the development of both societal and human has been recently realized. The health and wellbeing of the users of air-conditioning systems is significant as studies proposed that majority of people spent about $80 \%$ to $90 \%$ of their time at home (Yu and Lin, 2015). Moreover, the indoor environment scenario-based mathematical modelling is established in this paper to contribute to the sustainability of the proposed system. The material proposed is sustainable brick harmonizing the three bottom line principles namely; environment, social, and economic influences to meet the goals of today while considering future effects. In essence, the scenario modelling of indoor temperature and indoor air quality $\left(\mathrm{CO}_{2}\right)$ is revealed in the subsequent section.

\subsubsection{Scenario Modelling of Indoor Temperature}

The temperature of the indoor is influenced via the indoor environment air temperature, loss of heat from the wall, room volume and heater. Therefore, the temperature of the indoor environment can be stated in view of the principle of energy conservation as follows:

$$
\rho_{a} \cdot C_{\rho} \cdot V_{i} \cdot \frac{d T_{i}}{d \tau}=C-U_{w} \cdot A_{w} \cdot\left(T_{i}-T_{o}\right)
$$

For the time is $\tau(S)$, temperature of the indoor is $\left(T_{i}{ }^{\circ} \mathrm{C}\right)$, the total wall heat transfer coefficient is $U_{w}\left(W / m^{2} .{ }^{\circ} \mathrm{C}\right)$, wall area is $\left(A_{w} m^{2}\right)$, temperature of the outdoor is $\left(T_{o}{ }^{\circ} \mathrm{C}\right)$, heater work rate $U_{h 1}(W)$, room volume is $\left(V_{i} m^{3}\right)$, air heat capacity is $C_{p}\left(j / k g .{ }^{\circ} \mathrm{C}\right)$ and air density is $\rho_{a}\left(\mathrm{~kg} / \mathrm{m}^{3}\right)$ Accordingly, $U_{w}$ in equation (2) can be calculated as: (Heat transfer coefficient, 2019).

$$
U_{w}=\frac{1}{\frac{1}{h_{A}}+\frac{d_{w}}{K_{b}}+\frac{1}{h_{B}}}
$$




\section{Macrothink}

For the wall thickness is $d_{w}(m)$ and brick work thermal conductivity is $K_{b}\left(W / m .{ }^{\circ} \mathrm{C}\right)$, $h_{A}$ and $h_{B}\left(W / m^{3} .{ }^{\circ} \mathrm{C}\right)$ are basically the specific convection fluids transfer of heat coefficients on the wall of each sides. In view of this scenario, it is considered that $h_{A}=h_{B}=h_{\text {air }}$ and $h_{\text {air }}$ is the air convection transfer of heat coefficients.

Reflecting on equation (2), it can be conveyed into:

$$
U_{w}=\frac{1}{\frac{2}{h_{\text {air }}}+\frac{d_{w}}{K_{b}}}
$$

Utilizing Laplace transform, equation (3) can be expressed as:

$$
T_{i}(s) . s=\frac{1}{\rho_{a} \cdot V_{i} \cdot C_{p}} \cdot Q_{h 1}(s)-\frac{U_{w} \cdot A_{w}}{\rho_{a} \cdot V_{i} \cdot C_{p}} \cdot\left(T_{i}(s)-T_{o}(s)\right)
$$

Subsequently, the calculation can be designated as:

$$
\left(\frac{U_{w} \cdot A_{w}}{\rho_{a} \cdot V_{i} \cdot C_{p}}\right) \cdot T_{o}(s)=\frac{1}{\rho_{a} \cdot V_{i} \cdot C_{p}} \cdot Q_{h 1}(s)+\frac{U_{w} \cdot A_{w}}{\rho_{a} \cdot V_{i} \cdot C_{p}} \cdot T_{o}(s)
$$

Suppose $\frac{U_{w} \cdot A_{w}}{\rho_{a} \cdot V_{i} \cdot C_{p}} T_{o}(s)=0$, therefore equation (5) can be simplified and expressed as follows:

$$
\frac{T_{o}(s)}{Q_{h 1}(s)}=\frac{K_{i t}}{T_{i t} . S+1}
$$

For the constant of time is $T_{i t}=\frac{\rho_{a} \cdot V_{i} \cdot C_{p}}{U_{w} \cdot A_{w}} \quad$ and the function of transfer gain is $K_{i t}=\frac{1}{U_{w} \cdot A_{w}}$.

Likewise, $0.3 \mathrm{~m}$ is the wall thickness, 2.5 is the height, $2 \mathrm{~m}$ is the width and $3 \mathrm{~m}$ is the overall room length. Accordingly, the anticipated indoor temperature is assumed to be $20^{\circ} \mathrm{C}$. Subsequently, flow rate volume $f=0.01 \mathrm{~m}^{3} / \mathrm{s}, d_{w}=0.3 \mathrm{~m}, A_{w}=25 \mathrm{~m}^{2}$ and $V_{i}=15 \mathrm{~m}^{3}$. Therefore, scrutinizing the table of coefficient via Tools and Basic Information for Design, Engineering and Construction of Technical Applications (2018), this paper can obtain: $H=2538 \mathrm{~kJ} / \mathrm{kg}, h_{\text {air }}=10 \mathrm{~W} / \mathrm{m}^{2} .{ }^{\circ} \mathrm{C}, \quad K_{b}=0.6 \mathrm{~W} / \mathrm{m} .{ }^{\circ} \mathrm{C}, C_{p}=1005 \mathrm{~J} / \mathrm{kg} \cdot{ }^{\circ} \mathrm{C}$ and $\rho_{a}=1.2 \mathrm{~kg} / \mathrm{m}^{3}$.

Consequently, through utilizing equation (3), it can be expressed as follows in equation (7), (8) and (9).

$$
U_{w}=\frac{1}{\frac{2}{h_{\text {air }}}+\frac{d_{w}}{K_{b}}}=1.43 \mathrm{~W} / \mathrm{m}^{2} .{ }^{\circ} \mathrm{C}
$$

Then, $T_{i t}=\frac{\rho_{a} \cdot V_{i} \cdot C_{p}}{U_{w} \cdot A_{w}}=506.52$ 


$$
K_{i t}=\frac{1}{U_{w} \cdot A_{w}}=0.028
$$

\subsubsection{Scenario Modelling of Indoor Air Quality}

Research studies by Hui et al., (2006), Mui et al., (2008), and Wolkoff, (2013) suggested that there are diverse kinds of indoor contamination within the indoor environment and it is unimaginable to expect to control and monitor the entire indoor pollutants; hence, one contaminant that is predominant, which necessitates the utmost measure of natural air to weaken such pollutant to an adequate level is typically chosen in this examination as the control signal for the control methodology studied and the indicator analyzed is the $\mathrm{CO}_{2}$. $\mathrm{By}$ way of controlling indoor $\mathrm{CO}_{2}$ to the ideal levels, the greater part of the other indoor air contaminations may be kept-up at adequate levels. The concentration of the indoor $\mathrm{CO}_{2}$ cannbe specified as (Chao and $\mathrm{Hu}, 2004)$ :

$$
V_{i} \frac{d C_{i \mathrm{CO} 2}}{d \tau}=E_{\mathrm{CO} 2}-\lambda \cdot V_{i} \cdot C_{i \mathrm{CO} 2}-f \cdot\left(C_{i \mathrm{CO} 2}-C_{o \mathrm{CO} 2}\right)
$$

Hence, equation (10) can be expressed as:

$$
C_{i \mathrm{CO} 2}(t)=\frac{E_{\mathrm{CO} 2}+f \cdot C_{o \mathrm{CO} 2}}{\lambda \cdot V_{i}+f} \cdot\left(1-e^{-\frac{t}{T_{\mathrm{co} 2}}}\right)+C_{i o n} \cdot e^{-\frac{t}{T_{\mathrm{co} 2}}}
$$

For $T_{i \mathrm{CO} 2}=\frac{V_{i}}{\lambda \cdot V_{i}+f}$ is the system time constant

\subsubsection{The Smart Indoor System}

Consequently, the intelligent proportional integral derivative controller which is FLC dependent is projected for over-all control of the indoor environment quality. Fuzzy proportional integral derivative controllers can be inspected rather than direct proportional integral derivative controller in the entire applications of either modern or classical system control. The scheme basically converts the error amongst the reference and controlled or measured variable into an expected command that is like-wisely connected to process actuator. In reasonable plan, it is imperative to have data about their identical transfer of output-input qualities. For the fuzzy proportional integral derivative controller is essentially planned for the temperature and indoor air quality. Thus, temperature will be scrutinized as the signal control in-order to fundamentally depict the controller. The fuzzy proportional integral derivative controller that is self-tuning fundamentally comprises of two major divisions:

- fuzzy logic controller as revealed in Figure 9 and,

- proportional integral derivative controller

The controller of fuzzy logic is scrutinized for regulating the proportional integral derivative parameters on-line which is the $k_{p}, k_{i}$ and $k_{d}$ through the rules of the fuzzy logic control for improved control performance of the proportional integral derivative in diverse circumstances. Also, he anticipated controller of fuzzy proportional integral derivative is a design-based 
control auto-adaptive via the means of utilizing controller of incremental fuzzy logic. The controller of the proportional integral derivative is scrutinized for control of the indoor environment.

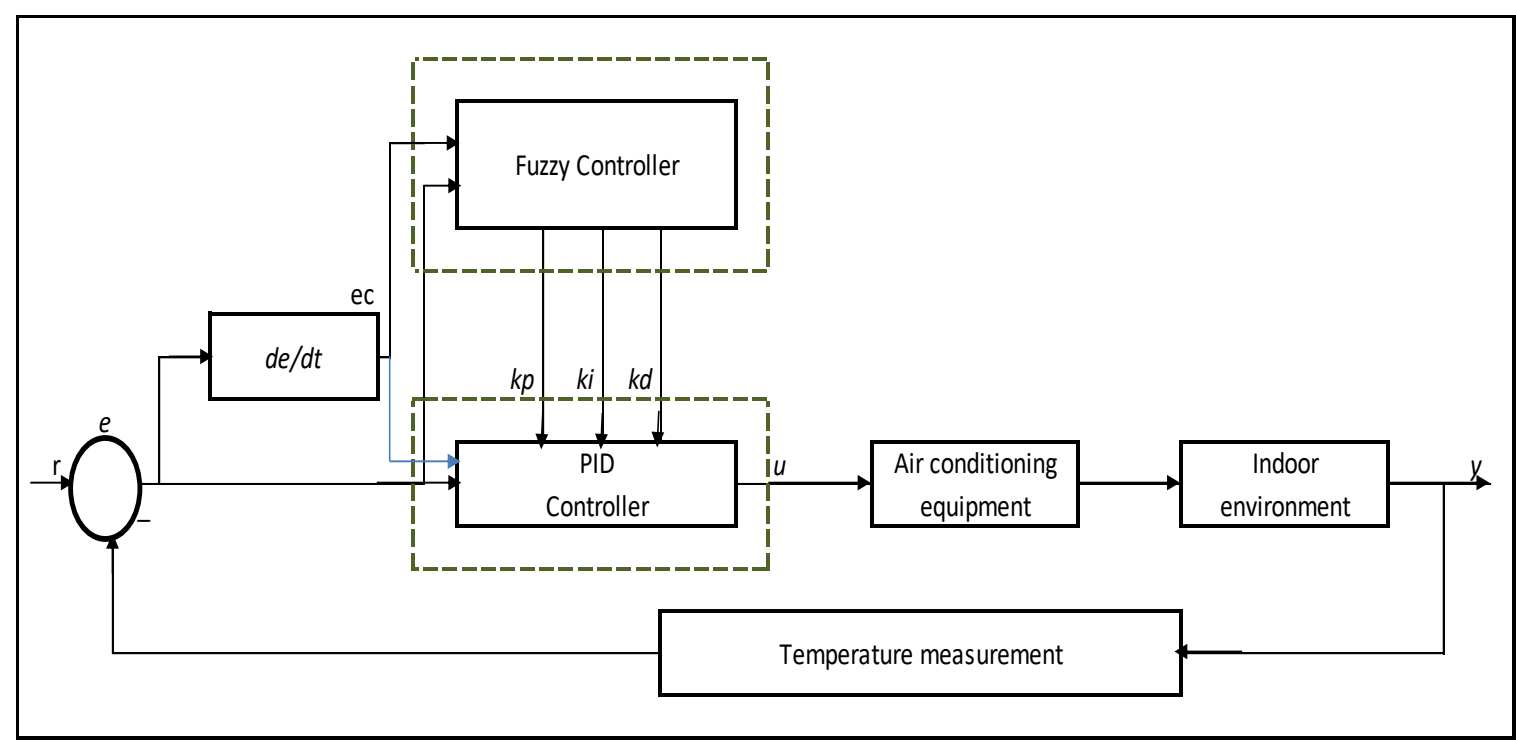

Figure 9. Fuzzy proportional integral derivative controller structure

The parameters of proportional integral derivative fuzzy self-tuning are to mainly discover the association of fuzzy amongst three proportional integral derivative parameters and likewise the $e c$ and $e$. Grounded upon output $y$ and input $r$, the system output $y$ is measured and subsequently, $e c$ and $e$ is calculated. For the objects that are controlled to accomplish improved dynamic stable execution, the controller of fuzzy logic fundamentally tunes the three $\left(k_{p}, k_{i}\right.$ and $\left.k_{d}\right)$ parameters through the rules of fuzzy control on-line. Therefore, it is required to know individual proportional integral derivative parameters functions. Subsequently, it is attainable to regulate the connection amongst $e c$ and $e$ which is the fuzzy input and $k_{p}, k_{i}$ and $k_{d}$ which is the fuzzy output and lastly to essentially construct the rule of the fuzzy logic. Subsequently, the projected fuzzy controller of proportional integral derivative that is self-tuning seeks to advance the control execution generated through the controller of proportional integral derivative. For it retains the basic controller of proportional integral derivative structure and may not compulsory alter portions of the hardware of the primary control system for execution. According to the research studies by Mui et al., (2008) and Song et al., (2013), exploring the entire kinds of indoor air contaminants for the over-all air quality control and monitoring is a difficult situation. However, Persily, (1997); Committee of European Normalization, (1998) and ASTM, (2003), instructed that the concentration of indoor $\mathrm{CO}_{2}$ (carbon dioxide) analysis and measurement may be beneficial for comprehending ventilation and indoor air quality efficiency. The indoor air quality control trouble is the dimension errors and delay of time. Nonetheless, for the goal to attain the system best performance regarding small overshoot, interference resistance, systemic stability and response speed for optimum sustainability goal, a back-propagation neural network that is based upon algorithm weight update with proportional-integral-derivative controller is anticipated. Therefore, the smart control systems for regulating indoor air quality of the 
renewable air-conditioning is vital in achieving a healthy living environment for the building inhabitants. With an appropriate smart control technique of proportional integral derivative controller, the indoor air quality can be significantly improved. The anticipated smart control for renewable air-conditioning can demonstrate accomplishment in exceptional control performance and occupants' comfort improvement.

\subsection{The Economic}

An economy that delivers standards of good living, the facilities that individuals need, and occupations is essential for society sustainability. A sustainable society needs continuing economic development somewhat than unbiassed economic growth. What happens currently is the economic growth which is frequently measured as growth in gross local product where consumerist economies rely upon economic growth to produce prosperity and occupations. For this reason, studies by Aghbashlo and Rosen, (2018), unfolded that the economy functions within a globe possessing limited capacities and resources, over the long term, a constantly growing economy is not inevitably sustainable. Hence, the universal economy must function more in a stable-state manner, with zero or little development. This fundamentally suggests that the economic assessment of the renewable smart air-conditioning must be equated as stable-state manner irrespective of the financial profitability analysis outcome in order to promote economic growth and the system benefits to the society since a growing economy is not certainly sustainable.

\subsubsection{Profitability Concept}

The meaning of profitability is the capability to create profit from the entire business pursuits of a firm, company, enterprise, organization or a system. It demonstrates by what means the productivity of the administration may produce profit through utilizing the entirely possessions accessible in the marketplace. Research studies by Harward and Upton (1961), suggested that productivity or efficiency is the capability of a specified asset to make a return as a result of its utilization. Nevertheless, the expression represented as 'Efficiency' is not tantamount to the expression characterized as 'Profitability'. Profitability is basically an efficiency index; and is subsequently viewed as efficiency measure and administration lead to better efficiency. Albeit, profitability is a vital standard for determining the efficiency, the profitability extent is unable to be confiscated as a concluding efficiency proof. Occasionally, acceptable profits can symbolize inefficiency and on the contrary, a suitable efficiency degree can go together with profit absence. Also, figure of the net profit basically discloses an acceptable steadiness amongst the received values and given value. Although, operational productivity change is just among the influences upon which an enterprise profitability mainly relies upon. Hence, it can be presumed that profit is not fundamentally the key mutable upon which the foundation of an organization financial and operational productivity may be equated. For the reason to quantify the efficiency of assets utilized and also to quantify the efficiency of operation - the analysis of profitability is contemplated as one of the best methods. 


\section{Macrothink \\ Environmental Management and Sustainable Development \\ ISSN 2164-7682 \\ 2020, Vol. 9, No. 3}

\subsubsection{Using Economic Profitability Procedures}

According to Oye et al., (2020), cost of the system installation is determined according to the following grounds:

- the equipment costs are basically ascertained through its category

- costs are contingent upon the specific place and the category of building involved.

- it also relies upon the level of salary in the engineering domains in the specific environment.

Recent research studies by Oye et al., (2020) unfolded that photovoltaic electric of up to 2.5 $\mathrm{kWh} / \mathrm{d}$ is sufficient for home-based requirements and as consequence, all components examined is within the aforementioned specification. According to their studies, this implies that a $2.5 \mathrm{~kW}$ solar system will yield electricity of about $(2.35 \mathrm{kWh} \times 2.5 \mathrm{~kW})=5.9 \mathrm{kWh}$ per day, averaged through the year. This interprets into power of about $2,140 \mathrm{kWh}$ per year. The average cost of photovoltaic solar air-conditioning is $£ 3998.62$ which includes all the system components and installation cost. Studies revealed that solar system is becoming cheaper since $2.5 \mathrm{kWh}$ system cost about three times the current price of the system in the last twelve months (Oye et al., 2020). The financial profitability of the solar air-conditioning via calculating the accounting rate of return, net present value, payback period and the internal rate of return are presented as follows:

The formula for accounting rate of return is specified in the equation (12) below:

$$
A R R=\frac{\text { Average Annual Profit }}{\text { Initial Investment }} \times 100
$$

Average Annual Profit $=$ Revenue - Annual Maintenance Cost

Average Annual Profit $=7500.00-75.00=7425.00$

$$
A R R_{20}=\frac{7500.00}{3998.62} \quad X 100=185.7 \%
$$

The formula for the net present value is expressed in the equation (14) below:

$$
N P V=\Sigma \frac{C_{i}}{(1+r)^{n}}-\text { Initial Investment }
$$

Where $C_{i}$ is the cash flow generated per year; $r$ is the rate of inflation and $n$ is the number of years. Table 3 presents the system annual income, operating profit and cash flows. However, higher net present values are advantageous and the rule for precise decision is as follows:

- $\quad N P V \leq 0$, reject project

- $\quad N P V>0$, accept project

$$
\text { Annual Income }=(0.149 \times 2140)+(0.0464 \times 2140)=£ 418.16
$$


The NPV in equation (14) can further be expressed as:

$$
\begin{gathered}
\frac{C_{i}}{(1.05)^{1}}+\frac{1.04 C_{i}}{(1.05)^{2}}+\frac{1.04 C_{2}}{(1.05)^{3}}+\frac{1.04 C_{3}}{(1.05)^{4}}+\frac{1.04 C_{4}}{(1.05)^{5}}+\cdots \frac{1.04 C_{n}}{(1.05)^{n}} \\
N P V=6347.20-3998.62=£ 2348.58
\end{gathered}
$$

Table 3. The system annual income, operating profit and cash flows (Oye et al., 2020)

\begin{tabular}{|l|l|l|l|l|l|}
\hline Annual & $\begin{array}{l}\text { Initial } \\
\text { Investment }\end{array}$ & Income & $\begin{array}{l}\text { Annual } \\
\text { Maintenance Cost }\end{array}$ & $\begin{array}{l}\text { Operating } \\
\text { Profit }\end{array}$ & Cash Flow \\
\hline Year 0 & $-£ 3998.62$ & - & - & - & - \\
\hline Year 1 & - & 418.16 & 75.00 & 343.16 & 343.16 \\
\hline Year 2 & - & 434.89 & 75.00 & 359.89 & 359.89 \\
\hline Year 3 & - & 452.23 & 75.00 & 377.23 & 377.28 \\
\hline Year 4 & - & 470.32 & 75.00 & 395.32 & 395.37 \\
\hline Year 5 & - & 489.13 & 75.00 & 414.13 & 414.19 \\
\hline Year 6 & - & 508.70 & 75.00 & 433.70 & 433.76 \\
\hline Year 7 & - & 529.05 & 75.00 & 454.05 & 454.11 \\
\hline Year 8 & - & 550.21 & 75.00 & 475.21 & 475.27 \\
\hline Year 9 & - & 572.22 & 75.00 & 497.22 & 497.28 \\
\hline Year 10 & - & 595.11 & 75.00 & 520.11 & 520.17 \\
\hline Year 11 & - & 618.91 & 75.00 & 543.91 & 543.98 \\
\hline Year 12 & - & 643.67 & 75.00 & 568.67 & 568.74 \\
\hline Year 13 & - & 669.42 & 75.00 & 594.42 & 594.49 \\
\hline Year 14 & - & 696.20 & 75.00 & 621.20 & 621.27 \\
\hline Year 15 & - & 724.05 & 75.00 & 649.05 & 649.12 \\
\hline Year 16 & - & 753.01 & 75.00 & 678.01 & 678.08 \\
\hline Year 17 & - & 783.13 & 75.00 & 708.13 & 708.21 \\
\hline Year 18 & - & 814.46 & 75.00 & 739.46 & 739.53 \\
\hline Year 19 & - & 847.04 & 75.00 & 772.04 & 772.12 \\
\hline Year 20 & - & 880.92 & 75.00 & 805.92 & 806.00 \\
\hline
\end{tabular}

The formula employed for the payback period can be expressed in equation (17) as:

$$
\text { Payback Period }=\frac{\text { Initial Investment }}{\text { Periodic Cash Flow }}
$$

As a result of an uneven cash flow and to determine how much time to recover the original investment, the payback period can further be expressed as:

$$
\text { Payback }=\text { Years before full recovery }+\frac{\text { Unrecovered cost at start of the year }}{\text { Cash flow during the year }}
$$

Also, the unrecovered cost at the start of the year = Initial Investment - Cash flows by the end of year 9. Subsequently, the payback period is expressed and calculated as follows: 


$$
\begin{gathered}
\text { Payback }=9+\frac{248.31}{520.17} \\
\text { Payback period }=9.5 \text { years }
\end{gathered}
$$

The internal rate of return is $10.19 \%$ and is calculated through IRRCalculator.net software programme. Subsequently, the analysis depicted that the project is worth undertaking through utilizing a sustainable and renewable means of technology. The economic sustainability opinions are divided into categories of strong and weak sustainability where the 'strong' focus more on the environment while the 'weak' focused more on the system financial assessment. However, it is beneficial to focus more on the strong sustainability of the renewable smart air-conditioning for the overall welfare of the society for constant economic growth.

\section{Remarks}

The use of air-conditioning has generally been applied as a result of the life-threatening summer conditions. There are probably always air-conditioning in indoors from offices to every room in the household which subsequently adds to the level of energy consumption and carbon emissions, and thereby causing climate change. Nevertheless, with so much contact to air-conditioning, there has been a continued debate as to whether the air-conditioning has an adverse effect on the human body and subsequently adds to the level of energy consumption and carbon emissions. Yes, is the answer to such question. However, studies also unveiled that human health is considered as the vocal point when considering sustainability. According to several studies, inhabitants in buildings with constant use of air-conditioning have higher illness rates with high level of energy consumption than individuals in buildings with natural ventilation. Study demonstrates that individuals who work in an environment that is over-air-conditioned can possibly experience constant fatigue and chronic headaches and also creates financial disadvantages for the individuals who have to pay for the power due to the high rates of energy consumption. Individuals who work or live in structures which are regularly being pumped full of cool air can similarly experience persistent breathing difficulties and mucous membrane irritation. This leaves individuals further helpless to contracting the flu, colds and other illnesses associate with the utilization of air-conditioning.

Air-conditioning may come-in convenient on a certainly hot day; nonetheless, it is likewise the worst offender for circulating micro-organisms and germs that cause breathing difficulties and yet, increasing the rates of energy consumption and carbon emissions. According to recent study directed at Louisiana State Medical Centre, eight categories of mould reside in 22 out of 25 indoors tested. Besides, residing in the air-conditioning zones for a lengthy period can potentially cause eyes, nose and throat respiratory problems. Air-conditionings are well-recognized to air-borne diseases circulation such as Legionairre's Disease, a possibly deadly infectious disease that gives rise to pneumonia and high fever. It likewise assists with rhinitis circulation, a disorder which causes the nose mucous membrane inflammation. Indoor occupants are further expected to become dehydrated due to poor indoor air quality in an area with unregulated air-conditioning as equated to other areas with regulated air-conditioning. The regulated air-conditioning can further be smart controlled through an appropriate smart 
control technique of proportional integral derivative controller to optimize indoor air quality within the indoor environment. The unregulated air-conditioning sucks humidity from the apartment while leaving inhabitants dehydrated and with the necessity to drink water. Dehydration emanating from air-conditioning utilization can cause migraines and headaches. Unexpected contact to the sun or heat after a lengthy contact to air-conditioning might cause headache. Likewise, in cases of air-conditioning housings which are not appropriately sustained, inhabitants are further susceptible to migraines and headaches. Unregulated contact to air-conditioning can possibly cause dry and itchy skin and eyes. Individuals having symptoms of dry eyes are recommended not to reside for too long in air-conditioning zones since it deteriorates effects whereas, extreme contact to air-conditioning alongside with sun contact can make the skin itchy and dry. The utilizations of central air-conditioning systems are also well-recognized to boost the effects of the disease that inhabitants may hitherto be suffering from. Air-conditioning is infamous for increasing the rates of energy consumption and carbon emissions and thereby causing climate change, and subsequently, it intensifies the indications of low blood pressure while making management of pain further problematic for individuals obstinate on utilizing their central air-conditioning. Nevertheless, this paper has unveiled the sustainable theoretical assessment from the principles of sustainability to challenge these problems.

\section{Conclusion}

Sustainability is measured as a technique for the industry to protect the environment. The promotion of sustainable practices is to typically pursue a balance between environment, economic and social performance in project applications. If we admit this, the connection amongst renewable energy and smart control for sustainability of air-conditioning becomes clear; air-conditioning is of strong environmental significance and subsequently has high economic and social influences. Due to increase awareness of environmental protection, this issue of energy consumption and carbon emissions emanating from the use of air-conditioning systems and its resultant health effects has sequentially gained worldwide attention. Unfolding sustainable theoretical framework for renewable smart air-conditioning practices has been underpinned as a typical way forward in promoting economic and social improvement in the air-conditioning manufacturing while minimizing the effects on the environment and human health. In pursuance of diminishing these unfavorable effects on the environment and to subsequentially attain sustainability in the industrial sector; three principles of sustainability, the sustainable indicators - propositions and prospects appeared. For they sequentially form the theoretical framework for unifying the principles of sustainability into the study of air-conditioning right from the theoretical phase.

The components of the photovoltaic solar air-conditioning were simulated in Polysun software, and the results unveiled that the system can provide the required yearly energy yield without compromise. Also, the simulation results of photovoltaic solar air-conditioning uncover the importance of using renewable as a source of clean energy in air-conditioning systems and the particular contribution it makes to the level of energy consumption and carbon emission. The system significantly demonstrates the importance of using solar energy as alternatives to fossil fuel to power air-conditioning systems, vis-à-vis combatting global 
warming and climate change and hereby promoting sustainable development. Consequently, the indoor environment quality has fundamentally influenced inhabitants' wellbeing, individuals' efficiency and comfort feelings. Thus, significant factors of the indoor environment must be properly controlled for growing request of everyday comforts. As a result, the anticipated smart control of temperature and indoor $\mathrm{CO}_{2}$ regulator possesses high-quality execution on controlling indoor temperature and indoor $\mathrm{CO}_{2}$ since the indoor environment can be effectively regulated through the proportional integral derivative controller. Therefore, the anticipated smart control system can optimize thermal comfort and eradicate the indoor environment health effects. Subsequently, the economic assessment of the solar-based system demonstrates how significant savings can be achieved through utilizing a sustainable and renewable means of technology - the photovoltaic solar air-conditioning technology. Each financial assessment indicators depicted that the project is worth undertaking. Therefore, the photovoltaic solar air-conditioning demonstrated to reduce the level of energy consumption and carbon emissions and also saves investment costs; it however proves to meet the sustainability agenda of the three pillars of sustainability. As a result, there is development, steadiness and productivity of the system for greener solutions to the worlds energy requirements.

The sustainable theoretical framework has substantial feasibility to speed up the understanding and application of renewable energy and smart control of air-conditioning in the industry sector. This theoretical framework via employing the principles of sustainability undoubtedly substantiated the significance of renewable smart air-conditioning in the sustainable development to reduce energy consumption, $\mathrm{CO}_{2}$ emissions and the resultant health effects. The full modelling of the smart indoor temperature and indoor $\mathrm{CO}_{2}$ control which is accessible in the analytical grid of the proposed sustainable theoretical framework (i.e. fuzzy logic control, proportional-integral-derivative, back-propagation neural network) will be further described and thoroughly examined in the analytical work presently underway.

\section{References}

Aghbashlo, M., \& Rosen, M. A. (2018). Exergoeconoenvironmental Analysis as a New Concept for Developing Thermodynamically, Economically, and Environmentally Sound Energy Conversion Systems. Journal of Cleaner Production, 187, 190-204.

https://doi.org/10.1016/j.jclepro.2018.03.214

ASTM. (2003). Standard guide for using indoor carbon dioxide concentrations to evaluate indoor air quality and ventilation, D6245-98, (reapproved 2002).

Berthiaume, R., \& Rosen, M. A. (2017). Limits Imposed by the Second Law of Thermodynamics on Reducing Greenhouse Gas Emissions to the Atmosphere. Research Journal of Environmental Sciences, 11(1), 18-28. https://doi.org/10.3923/rjes.2017.18.28

Chao, C. Y. H., \& Hu, J. S. (2004). Development of a dual-mode demand control ventilation strategy for indoor air quality control and energy saving. Building and Environment, 39, 385-391. https://doi.org/10.1016/j.buildenv.2003.11.001

Committee of European Normalization. (1998). Ventilation for buildings: design criteria for 
the indoor environment. Brussels, Luxembourg: Commission of the European Communities, Directorate General for Science, Research and Development Joint Research Centre-Environment Institute, CR1752.

Cooling Machine Manufactory. (2019). Nibe Industrier AB. [Online] Available: www.nibe.com

Daly, H. E. (1990). Toward some operational principles of sustainable development. Ecological Economics, 2, 1-6. https://doi.org/10.1016/0921-8009(90)90010-R

Dempsey, N., Bramley, G., Power, S., \& Brown, C. (2011). The social dimension of sustainable development: defining urban social sustainability. Sustainable Development, 19, 289-300. https://doi.org/10.1002/sd.417

Dewulf, H., Van Langenhove, H., Mulder, J., van den Berg, M. M. D., van der Kooi, H. J., \& de Swaan Arons., J. (2000). Illustrations towards quantifying the sustainability of technology. Green Chemistry, 2, 108-114. https://doi.org/10.1039/b000015i

Evans, A., Strezov, V., \& Evans, T. J. (2009). Assessment of sustainability indicators for renewable energy technologies. Renewable and Sustainable Energy Reviews, 13, 1082-1088. https://doi.org/10.1016/j.rser.2008.03.008

Gnanapragasam, N. V., Reddy, B. V., \& Rosen, M. A. (2011). Sustainability of an energy conversion system in Canada involving large-scale integrated hydrogen production using solid fuels. International Journal of Energy and Environment, 2(1), 1-38.

Gomez-Echeverri, L., Johansson, T. B., Nakicenovic, N., \& Patwardhan, A. (Eds.) (2012). Global Energy Assessment: Toward a Sustainable Future. Cambridge, Vienna: International Institute for Applied Systems Analysis, Vienna, and Cambridge University Press.

Gugulothu, R., Somanchi, N. S., Banoth, H. B., \& Banothu, K. (2015). A Review on Solar Powered Air Conditioning System. Global Challenges, Policy Framework and Sustainable Development for Mineral and Fossil Energy Resources (GCPF2015). Procdia arth and planetary science, 11, 361-367. https://doi.org/10.1016/j.proeps.2015.06.073

Hacatoglu, K., Dincer, I., \& Rosen, M. A. (2016). Sustainability Assessment of a WindHydrogen Energy System: Assessment Using a Novel Index and Comparison to a Conventional Gas-Fired System. International Journal of Hydrogen Energy, 41(19), 8376-8385. https://doi.org/10.1016/j.ijhydene.2016.01.135

Harward, M., \& Upto, K. (1961). Introduction to Business Finance. Mc Graw Hill, New York.

Heat Transfer Coefficient, (2019). Available at:

https://en.wikipedia.org/wiki/Heat_transfer_coefficient

Hui, P. S., Wong, L. T. \& Mui, K. W. (2006). Feasibility study of an express assessment protocol for the indoor air quality of air-conditioned offices. Indoor and Built Environment, 15(4), 373-378. https://doi.org/10.1177/1420326X06067866 
Khalid, F., Dincer, I., \& Rosen, M. A. (2015). Development and analysis of sustainable energy systems for building HVAC applications. Applied Thermal Engineering, 87, 389-401. https://doi.org/10.1016/j.applthermaleng.2015.04.015

Kjellström, T., Holmer, I., \& Lemke, B. (2009). Workplace heat stress, health and productivity an increasing challenge for low-and middle-income countries during climate change. Glob Health Action, 2(1). https://doi.org/10.3402/gha.v2i0.2047

Krajacic, G., Duic, N., \& Rosen, M. A. (2015). Sustainable development of energy, water and environment systems. Energy Conversion and Management, 104, 1-7.

https://doi.org/10.1016/j.enconman.2015.07.076

Krajacic, G., Vujanovic, M., Duic, N., Kilkis, S., Rosen, M. A., \& Al-Nimr, M. A. (2018). Integrated Approach for Sustainable Development of Energy, Water and Environment Systems. Energy Conversion and Management, 159, 398-412.

https://doi.org/10.1016/j.enconman.2017.12.016

Mansoori, A., Enayati, N., \& Agyarko, L. B. (2016). Sources, Utilization, Legislation, Sustainability, Illinois as Model State. World Scientific Publishing Co. Hackensack, NJ 2016.

Mauthner, F., \& Weiss, W. (2014). Solar Heat Worldwide Markets and Contribution to the Energy Supply. - Gleisdorf, Austria: IEA Solar Heating \& Cooling Programme, 2014. p. 61. https://doi.org/10.18777/ieashc-shw-2014-0001

Morse, S., \& Fraser, E. D. G., (2005). Making "dirty" nations look clean? The nation state and the problem of selecting weighting indices as tools for measuring progress towards sustainability. Geoforum, 36, 625-640. https://doi.org/10.1016/j.geoforum.2004.10.005

Mui, K. W., Wong, L. T., Hui, P. S., \& Law, K. Y. (2008). Epistemic evaluation of policy influence on workplace indoor air quality of Hong Kong in 1996-2005, Building Services Engineering Research and Technology, 29(2), 157-164.

https://doi.org/10.1177/0143624408089522

Nazzal, Y., Abuamarah, B. A., Kishawy, H. A., \& Rosen, M. A. (2013). Considering environmental sustainability as a tool for manufacturing decision making and future development. Research Journal of Environmental and Earth Sciences, 5(4), 193-200.

https://doi.org/10.19026/rjees.5.5714

Oye, T. T. (2018). Mass retrofitting of an energy efficient low carbon zone, Thesis.

Oye, T. T., Goh, K., Gupta, N., \& Oye, T. K., (2020). Assessment of Renewable Air-Conditioning Using Economic Feasibility Procedures. International Journal of Innovative Science and Research Technology, 5(3).

Persily, A. K. (1997). Evaluating building IAQ and ventilation with indoor carbon dioxide. ASHRAE Transactions, 103(2), 193-203.

Russell-Smith, S. V., Lepech, M. D., Fruchter, R., \& Meyer, Y. B. (2015). Sustainable target value design: integrating life cycle assessment and target value design to improve building 


\section{Macrothink \\ Environmental Management and Sustainable Development \\ ISSN 2164-7682 2020, Vol. 9, No. 3}

energy and environmental performance. J. Clean. Prod, 88, 43-51.

https://doi.org/10.1016/j.jclepro.2014.03.025

Siddqui, Z., Ansari, A. J., \& Minai, A. F. (2015). Smart control of Air conditioning system for thermal comfort. International Journal of Application or Innovation in Engineering \& Management (IJAIEM), 4(3).

Smil, V. (2007). Energy in Nature and Society: General Energetics of Complex Systems, Cambridge, MA: MIT Press.

Song, Y., Wu, S., \& Yan, Y., (2013). Development of Self-Tuning Intelligent PID Controller Based on 115 for Indoor Air Quality Control. International Journal of Emerging Technology and Advanced Engineering, 3(11), 283-290.

Wang, Z., Wang, L., Dounis, A. I., \& Yang, R. (2012). Multi-agent control system with information fusion-based comfort model for smart buildings. Applied Energy, 99, 247-254. https://doi.org/10.1016/j.apenergy.2012.05.020

Wilhite, H. (2009). The conditioning of comfort. Build. Res. Inf., 37, 84-88.

https://doi.org/10.1080/09613210802559943

Wolkoff, P. (2013). Indoor air pollutants in office environments: Assessment of comfort, health, and performance. International Journal of Hygiene and Environmental Health, 216, 371-394. https://doi.org/10.1016/j.ijheh.2012.08.001

Yu, C., \& Lin, C. (2015). An Intelligent Wireless Sensing and Control System to Improve Indoor Air Quality: Monitoring, Prediction, and Pre-action. International Journal of Distributed Sensor Networks, 2015, 1-9. https://doi.org/10.1155/2015/140978

\section{Copyright Disclaimer}

Copyright for this article is retained by the author(s), with first publication rights granted to the journal.

This is an open-access article distributed under the terms and conditions of the Creative Commons Attribution license (http://creativecommons.org/licenses/by/4.0/). 